\title{
Is Spontaneous Pneumomediastinum a Poor Prognostic Factor in Covid-19?
}

\author{
Ibrahim Ethem Ozsoy ${ }^{1}$, Mehmet Akif Tezcan ${ }^{1}$, Seda Guzeldag ${ }^{2}$ and Ayse Turunc Ozdemir ${ }^{3}$ \\ ${ }^{1}$ Department of Thoracic Surgery, Kayseri Health Practice and Research Centre, University of Health Sciences, Turkey \\ ${ }^{2}$ Department of Intensive Care Unit, Kayseri Health Practice and Research Centre, University of Health Sciences, Turkey \\ ${ }^{3}$ Department of Infection Diseases, Kayseri Health Practice and Research Centre, University of Health Sciences, Turkey
}

\begin{abstract}
Objective: To determine the risk factors for spontaneous pneumomediastinum (SPM), its clinical course and effect on prognosis in patients with Coronavirus disease-19 (COVID-19) pneumonia.

Study Design: Descriptive study.

Place and Duration of Study: Kayseri City Training and Research Hospital, Turkey, from April to September 2020.

Methodology: All COVID-19 patients' clinical, laboratory, and radiologic characteristics, as well as treatment outcome data, were obtained through medical record extraction. Group A had 50 patients (22 men and 28 women) without SPM, and Group B had 20 patients ( 10 men and 10 women) with SPM.

Results: Considering the accompanying comorbidities, the frequencies of asthma and inhaler-use was significantly higher in Group B than in Group A ( $p<0.05)$. In the CT evaluation at presentation, the rate of involvement of all five lobes of the lung in Group B was significantly higher than in Group A. Rates of tube thoracostomy, mechanical ventilator requirement, length of stay in hospital, and exitus were significantly higher in Group B than in Group A ( $p<0.05)$.

Conclusion: SPM development in a patient with COVID-19 pneumonia is a sign that the prognosis will not be good, and these patients need a more aggressive treatment.
\end{abstract}

Key Words: Spontaneous pneumomediastinum, COVID-19, Pneumothorax, Real-time polymerase chain reaction, Subcutaneous emphysema.

How to cite this article: Ozsoy IE, Tezcan MA, Guzeldag S, Ozdemir AT. Is Spontaneous Pneumomediastinum a Poor Prognostic Factor in Covid-19?. J Coll Physicians Surg Pak 2021; 31(02):132-137.

\section{INTRODUCTION}

The disease caused by the severe acute respiratory syndrome-coronavirus-2 (SARS-CoV-2), which is a member of the coronavirus family, has been named as the coronavirus disease- 19 (COVID-19). This virus's most important feature is that it rapidly spreads from person to person through droplets and contact. Because of this feature, it has affected large masses within a short period of time. COVID-19 can affect many organs, including the lungs as well as the brain, kidneys and liver. The most affected organ involvement, which has an effect on mortality, is the lung. ${ }^{1,2}$ Although the gold standard in the diagnosis of the disease is the real-time polymerase chain reaction (RT-PCR) test; computed tomography (CT) of the chest is extensively used because of the inadequacy in the performance of the test in some areas and the possibility of its falsenegativity in the early period.

Correspondence to: Dr. Ibrahim Ethem Ozsoy, Department of Thoracic Surgery, Kayseri Health Practice and Research Centre, University of Health Sciences, Turkey E-mail: ibrahimethem.ozsoy@sbu.edu.tr

Received: December 03, 2020; Revised: January 03, 2021;

Accepted: February 08, 2021

DOI: https://doi.org/10.29271/jcpsp.2021.02.132
However, the radiological methods are not screening tests in the diagnosis of COVID-19; and they should be used as methods that help diagnose and monitor the disease. ${ }^{3,4}$

Spontaneous pneumomediastinum (SPM) is a rare disease characterised by the presence of free air in the mediastinum without any underlying cause. It does not occur because of mechanical ventilation; and occurs without any trauma oriatrogenic intervention. The pathophysiology of this condition is based on the existence of a pressure gradient between the alveoli and the lung interstitium. This pressure difference may lead to alveolar rupture and the consequent escape of air into the interstitium. ${ }^{5} \mathrm{SPM}$ complication has been rarely reported in COVID-19 patients receiving inpatient treatment.

Studies involving a large number of SPM patients are not available yet. ${ }^{6,7}$ In the present study, it was aimed to reveal the predisposing and precipitating factors for SPM, its clinical course, and effecton prognosis in patients with COVID-19 pneumonia.

\section{METHODOLOGY}

The study was approved by the Local Ethics Committee (Date: 01.10.2020 / No: 165) and conducted in accordance with the 
principles of the Declaration of Helsinki. After obtaining permission from the Department of Thoracic Surgery, Kayseri City Training and Research Hospital, Kayseri, Turkey, and Hospital Education Board, data from the Hospital Information Management System were retrospectively reviewed. All COVID-19 patients' clinical, laboratory, and radiologic characteristics, as well as data on treatment outcomes, were retrieved through extraction of medical records. The recorded information included demographic data, medical history, potential comorbidities, symptoms, and CT scans. The follow-up and treatment of patients with COVID-19 pneumonia were performed according to the guidelines that were prepared and have been regularly updated by the Ministry of Health. Based on the patient's clinical presentation, hydroxychloroquine and/or favipiravir-/+ azithromycin (antibiotic may vary depending on culture results), and enoxaparin were given. Tocilizumab, convalescent plasma and corticosteroids were given to eligible patients. The control group patients, who did not develop SPM during the treatment, were named as Group A; and those who developed SPM during the treatment, were named as Group B. Patients with pneumomediastinum, who had known lung bullae in their previous CTs, were intubated, treated using a ventilator, exposed to barotrauma or trauma. Those who underwent tracheostomy were excluded from the study. A chest tube was applied to patients with pneumothorax, accompanying SPM. Risk factors leading to SPM as well as the effect on the treatment process and mortality after its development were investigated.

Mean, standard deviation, median, $25^{\text {th }}$ percentile, $75^{\text {th }}$ percentile, frequency and ratiovalues were used in the descriptive statistics of the data. The distribution of the variables was assessed with the Shapiro-Wilk test. Independent sample ttest and Mann-Whitney U-test were used in the analysis of quantitative independent data. Chi-square test was used in the analysis of qualitative independent data and Fischer Exact test was used when test conditions for the Chi-square test were not met. The independent factors associated with SPM were evaluated using univariate and multivariate logistic regression analysis. SPSS version 27.0 was used in the analyses. Values of $p<0.05$ were considered significant.

\section{RESULTS}

Patients from April to September 2020 were analysed. Group A had 50 patients ( 22 men and 28 women) without SPM; and Group B had 20 patients ( 10 men and 10 women) with SPM. The mean age was $60.6 \pm 13.6$ years in Group $A$, and it was $57.7 \pm 14.1$ years in Group B. The age and gender distributions of the patients in both groups did not significantly differ ( $p=0.425$ and $p=0.649$, respectively). Rates of symptoms, including dysphagia-odynophagia, swelling in the neck, and cough, were significantly higher in Group B than in Group A $(p=0.021, p<0.001$ and $p=0.014)$. Considering the accompanying comorbidities, the rate of asthma and inhaler use was significantly higher in Group B than in Group $A$ ( $p=0.015$ and $p=0.034)$. In Group $A$, the rate of hypertension (HT) was significantly higher $(p=0.003)$ than in Group B. Rates of diabetes mellitus (DM), chronic obstructive pulmonary disease (COPD), chronic renal failure (CRF), colon cancer, thyroid cancer, lung cancer, and coronary artery disease as well as history of steroid use did not differ significantly between both groups ( $p$ $>0.05$ ). In group B, SPM was accompanied by subcutaneous emphysema in 14 patients and pneumothorax in 4 patients. It is also accompanied by bilateral, multilobarground glassopacities (Figure 1).

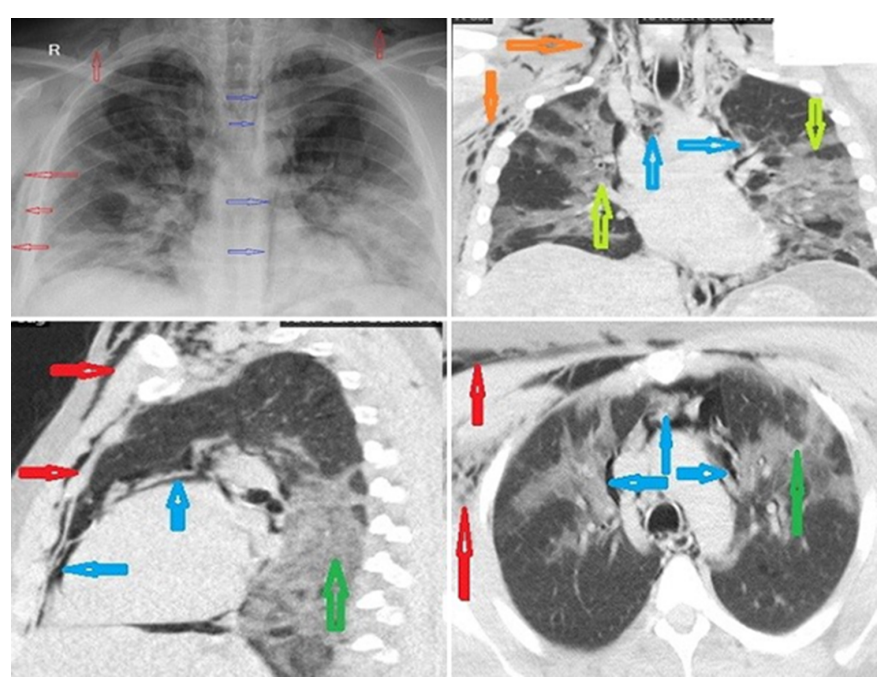

Figure 1: Chest X-ray and CT show spontaneous pneumomediastinum (blue arrows), subcutaneous emphysema (red arrows), and bilateral ground-glass opacities (green arrows) of the lung.

Three of these patients required tube thoracostomy. In the laboratory evaluation, there was no significant difference $(p>0.05)$ betweenthelymphocytevaluesatpresentationand thelymphocyte values measured consecutively during the treatment process in both groups. The $\mathrm{C}$-reactive protein (CRP) value at presentation did not significantly differ $(p=0.323)$ between both groups. The CRP value measured consecutively in Group B during treatment was significantly higher than in Group A $(p<0.001)$. The ferritin value at presentation did not significantly differ $(p=0.082)$ between both groups. In Group B, the ferritin value measured consecutively during the treatment process was significantly higher than in Group A $(p<0.001)$. In the $\mathrm{CT}$ evaluation at presentation, the rate of involvement of all five lobes of the lung in Group B was significantly higher than in Group A. The rates of involvement of two lobes and three lobes were significantly higher in Group A than in Group B ( $p=0.028$ and $p=0.014$ ). The rate of right upper lobe involvement and left upper lobe involvement in both groups did not differ significantly $(p>0.05)$. Rates of ground-glass-opacity, air bronchogram, bronchiectasis, pleural effusion, pericardial effusion, mediastinal lymphadenopathy, pleural thickening adjacent to the lesion, peripheral lesions and bilateral lesions did not significantly differ $(p>0.05)$ between both groups. 
Table I: Baseline demographic, laboratory, and radiological data and accompanying comorbidities of the patients.

\begin{tabular}{|c|c|c|c|}
\hline Parameters & $\begin{array}{c}\text { Group A } \\
\text { Mean } \pm \text { S.D/Median (IQR)/ } \\
\text { n (\%) }\end{array}$ & $\begin{array}{c}\text { Group B } \\
\text { Mean } \pm \text { S.D/Median (IQR)/ } \\
\text { n (\%) }\end{array}$ & $\mathbf{p}$ \\
\hline Age & $60.6 \pm 13.6$ & $57.7 \pm 14.1$ & $0.425^{t}$ \\
\hline $\begin{array}{l}\text { Gender: } \\
\text { Women } \\
\text { Men }\end{array}$ & $\begin{array}{l}28(56.0 \%) \\
22(44.0 \%)\end{array}$ & $\begin{array}{l}10(50.0 \%) \\
10(50.0 \%)\end{array}$ & $0.649^{x^{2}}$ \\
\hline $\begin{array}{l}\text { Clinical findings: } \\
\text { Chest pain } \\
\text { Dyspnea } \\
\text { Dysphagia-odynophagia } \\
\text { Neck pain } \\
\text { Cough }\end{array}$ & $\begin{array}{c}34(68.0 \%) \\
36(72.72 \%) \\
0(0.0 \%) \\
0(0.0 \%) \\
37(74.0 \%)\end{array}$ & $\begin{array}{c}9(45.0 \%) \\
19(95.0 \%) \\
3(15.0 \%) \\
14(70.0 \%) \\
20(100.0 \%)\end{array}$ & $\begin{array}{c}0.074^{\mathrm{X}} \\
0.051^{\mathrm{F}} \\
0.021^{\mathrm{F}} \\
<0.001^{\mathrm{F}} \\
0.014^{\mathrm{F}}\end{array}$ \\
\hline $\begin{array}{l}\text { Lymphocyte }(\mathrm{mL}) \text { : } \\
\text { Presentation } \\
\text { Consecutively }\end{array}$ & $\begin{array}{l}1025(625-1435) \\
1000(640-1265)\end{array}$ & $\begin{array}{c}1025(822.5-1807.5) \\
820(482.5-1267.5)\end{array}$ & $\begin{array}{l}0.677^{\mathrm{m}} \\
0.349^{\mathrm{m}}\end{array}$ \\
\hline $\begin{array}{l}\text { CRP (ug/L): } \\
\text { Presentation } \\
\text { Consecutively }\end{array}$ & $\begin{array}{l}1025(625-1435) \\
1000(640-1265)\end{array}$ & $\begin{array}{c}1025(822.5-1807.5) \\
820(482.5-1267.5)\end{array}$ & $\begin{array}{l}0.677^{\mathrm{m}} \\
0.349^{\mathrm{m}}\end{array}$ \\
\hline $\begin{array}{l}\text { Ferritin (ug/L): } \\
\text { Presentation } \\
\text { Consecutively }\end{array}$ & $\begin{array}{c}312(232-750) \\
320(210-591.3)\end{array}$ & $\begin{array}{c}503.5(239.3-1963) \\
1080.5(736.3-1372.3)\end{array}$ & $\begin{array}{l}0.082^{m} \\
<0.001^{m}\end{array}$ \\
\hline $\begin{array}{l}\text { Comorbidity: } \\
\text { Hypertension } \\
\text { Diabetes } \\
\text { Asthma } \\
\text { COPD } \\
\text { CRF } \\
\text { Colon cancer } \\
\text { Thyroid cancer } \\
\text { Lung cancer } \\
\text { CAD } \\
\text { Inhaler drug use }\end{array}$ & $\begin{array}{c}32(64.0 \%) \\
22(44.0 \%) \\
8(16.0 \%) \\
2(4.0 \%) \\
7(14.0 \%) \\
2(4.0 \%) \\
0(0.0 \%) \\
4(8.0 \%) \\
3(6.0 \%) \\
10(20.0 \%)\end{array}$ & $\begin{array}{l}5(25.0 \%) \\
7(35.0 \%) \\
9(45.0 \%) \\
0(0.0 \%) \\
0(0.0 \%) \\
1(5.0 \%) \\
1(5.0 \%) \\
2(10.0 \%) \\
2(10.0 \%) \\
9(45.0 \%)\end{array}$ & $\begin{array}{c}0.003^{\times 2} \\
0.490^{\times 2} \\
0.015^{\mathrm{F}} \\
>0.999^{\mathrm{F}} \\
0.178^{\mathrm{F}} \\
>0.999^{\mathrm{F}} \\
0.286^{\mathrm{F}} \\
>0.999^{\mathrm{F}} \\
0.619 \%^{\mathrm{F}} \\
0.034^{\times 2}\end{array}$ \\
\hline Pneumomediastinum & $0(0.0 \%)$ & $20(100.0 \%)$ & $<0.001^{\times 2}$ \\
\hline Subcutaneous Emphysema & $0(0.0 \%)$ & $14(70.0 \%)$ & $<0.001^{\mathrm{F}}$ \\
\hline Pneumothorax & $0(0.0 \%)$ & $4(20.0 \%)$ & 0.005 \\
\hline $\begin{array}{l}\text { CT findings: } \\
\text { One lobe } \\
\text { Two lobes } \\
\text { Three lobes } \\
\text { Four lobes } \\
\text { Five lobes } \\
\text { Right middle lobe } \\
\text { Right lower lobe } \\
\text { Left lower lobe } \\
\text { IST }\end{array}$ & $\begin{array}{c}0(0.0 \%) \\
15(30.0 \%) \\
13(26.0 \%) \\
0(0.0 \%) \\
22(44.0 \%) \\
32(64.0 \%) \\
27(54.0 \%) \\
25(50.0 \%) \\
2(4.0 \%)\end{array}$ & $\begin{array}{c}1(5.0 \%) \\
1(5.0 \%) \\
0(0.0 \%) \\
0(0.0 \%) \\
18(90.0 \%) \\
19(95.0 \%) \\
19(95.0 \%) \\
20(100.0 \%) \\
7(35.0 \%)\end{array}$ & $\begin{array}{c}0.286^{F} \\
0.028^{F} \\
0.014^{F} \\
>0.999^{F} \\
<0.001^{\times 2} \\
0.008^{\times 2} \\
0.001^{\times 2} \\
<0.001^{\times 1} \\
0.002^{F}\end{array}$ \\
\hline MVR & $0(0.0 \%)$ & $12(60.0 \%)$ & $<0.001^{F}$ \\
\hline Tube thoracostomy & $0(0.0 \%)$ & $3(15.0 \%)$ & $0.021^{\mathrm{F}}$ \\
\hline LOS (days) & $9(8-14)$ & $20.5(12.3-27.8)$ & $<0.001^{\mathrm{m}}$ \\
\hline Exitus & $2(4.0 \%)$ & $12(60.0 \%)$ & $<0.001^{\mathrm{F}}$ \\
\hline
\end{tabular}

Table II: Factors associated with spontaneous pneumomediastinum in patients with COViD-19 pneumonia.

\begin{tabular}{|c|c|c|c|c|}
\hline \multirow[b]{2}{*}{ CRP* } & \multicolumn{3}{|c|}{$\begin{array}{c}\text { Univariate analysis } \\
\text { OR \% } 95 \mathrm{Cl} \mathrm{p}\end{array}$} & $\begin{array}{l}\text { Multivariate analysis } \\
\text { OR } \% 95 \mathrm{Cl} \mathrm{p}\end{array}$ \\
\hline & 1.03 & $1.02-1.05$ & $<0.001$ & $1.06 \quad 1.01-1.120 .017$ \\
\hline Ferritin* & 1.00 & $1.00-1.00$ & $<0.001$ & \\
\hline Hypertension & 0.19 & $0.06-0.60$ & 0.005 & $\begin{array}{lll}0.05 & 0.00-0.54 & 0.014\end{array}$ \\
\hline Asthma & 4.30 & $1.35-13.72$ & 0.014 & \\
\hline Inhaler drug use & 3.27 & $1.07-10.04$ & 0.038 & \\
\hline Five lobes involvement & 11.46 & $2.40-54.73$ & 0.002 & \\
\hline IST & 12.92 & $2.39-69.81$ & 0.003 & $12.26 \quad 0.73-205.29 \quad 0.081$ \\
\hline Right middle lobe & 10.69 & $1.32-86.59$ & 0.026 & \\
\hline Right lower lobe & 16.19 & $2.01-130-38$ & 0.009 & $\begin{array}{lll}435.98 & 2.73-69528.58 & 0.019\end{array}$ \\
\hline LOS & 1.16 & $1.07-1.25$ & $<0.001$ & \\
\hline
\end{tabular}

The rate of using favipiravir, antibiotherapy, corticosteroid and enoxaparin for the purpose of treatment did not differ significantly $(p>0.05)$ between both groups. Rates of tube thoracostomy, mechanical ventilator requirement, length of stay in hospital (LOS), and exitus were significantly higher in Group B than in Group A ( $p<0.05)$. The demographic, labora- 
tory and radiological data and accompanying comorbidities of the patients are shown in Table I.

In the univariate model, CRP and ferritin values measured consecutively during the treatment process, hypertension, history of asthma and inhaler drug use, lesion formation in all five lobes, interlobular septal thickening, right middle lobe, and right lower lobe as well as LOS had a significant ( $p$ $<0.05$ ) effect in the division of patients into both groups. In the multivariate reduced model, CRP measured consecutively during the treatment process, hypertension and right lower lobe involvement had a significant-independent $(p=0.017, p=0.014$ and $p=0.019)$ effect in the division of patients into both groups (Table II).

\section{DISCUSSION}

Currently, the world is still under the influence of the COVID-19 pandemic, and the pandemic continues to affect the world as an important health problem because of its rapid transmission, high case fatality rate, and global impact on social welfare and the economy. Although COVID-19 seems to primarily affect the respiratory system, but it affects almost every system. The complications of COVID-19 include but are not limited to coagulopathy, disseminated intravascular coagulation, venous thromboembolism, massive pulmonary embolism, laryngeal oedema and laryngitis, fatal necrotising pneumonia, cardiovascular complications (acute pericarditis, left ventricular dysfunction, acute myocardial injury, arrhythmias and heart failure), acute respiratory distress syndrome, sepsis, septic shock and multiple organ failure, as well as ventilation-associated pneumonia and rarely pneumothorax and pneumomediastinum. ${ }^{6-8}$

SPM rarely develops in patients with COVID-19, but its effect on the patient is serious; however, there are a limited number of reports in the literature regarding this condition. The most common clinical signs and symptoms of SPM include sudden onset of retrosternal chest pain, dyspnea, dysphagia-odynophagia, hoarseness, neck pain, and subcutaneous emphysema. ${ }^{9,10}$ A typical physical examination finding is a crunching sound synchronous with the peak heart rate in auscultation on the anterior aspect of the chest, which is called the Hamman's sign. ${ }^{11}$ All of the patients included in this study were COVID-19 positive patients. The rates of dysphagia-odynophagia, subcutaneous emphysema, and cough were significantly higher in Group B than in Group A.

Although the exact mechanism of SPM is unknown, it may develop as a result of alveolar rupture due to the decrease in the pressure gradient between the lung interstitium and alveoli. SPM is generally self-limiting; however, the air can reach the neck through submandibular and retropharyngeal spaces between the tissue planes, as well as the diaphragm and retroperitoneum through the periaortic and perioesophageal planes. Consequently, it may cause serious circulatory and respiratory pathologies. There are some predis- posing and precipitating factors such as asthma, diving, weight lifting, strong cough, screaming, crying out loud, emesis, smoking, inhaled drug use, corticosteroids, inhalation of irritants and other conditions as well as some anatomical predisposing alterations., 52,13 In the present study, 45\% of Group B patients and $16 \%$ of Group A patients had asthma. The rate of inhaler use was $45 \%$ in Group B and $20 \%$ in Group A. Both were statistically significant between the groups.

The World Health Organisation's current estimate of the global case fatality rate is $2.5 \% .{ }^{14}$ Prognostic factors that have been associated with increased risk of unfavourable outcomes and mortality include age $\geq 50$ years, male gender, presence of comorbidities (e.g., hypertension, diabetes, cardiovascular or cerebrovascular disease, COPD, obesity and malignancy), lymphopenia, hepatic impairment, renal impairment or cardiac injury and elevated inflammatory markers (CRP, procalcitonin and ferritin). ${ }^{15,16}$ In the present study, there was no statistically significant difference between the groups in terms of age, gender and lymphocyte count, as well as rates of diabetes, coronary artery disease and malignancy. However, the CRP value measured consecutively during the treatment process and the ferritin value consecutively measured during the treatment process were significantly higher in Group B. Moreover, hypertension was found to be significantly higher in Group B.

CT is used extensively in the diagnosis and follow-up of COVID-19, and CT is the gold standard in the radiological diagnosis of patients with SPM. The most common imaging features on a CT typical of COVID-19 infection include bilateral, multilobar ground glass opacities with a peripheral or posterior distribution (or both), above all in the lower lobes and less frequently within the right middle lobe. ${ }^{17,18}$ In this study, the rates of right middle lobe, right lower lobe and left lower lobe involvement were significantly higher in Group B patients, who developed SPM. Moreover, $90 \%$ of Group B patients had lesions in all five lobes of the lung, while all five lobes were involved in $44 \%$ of Group A patients.

In patients with COVID-19, progressive pneumonia can cause SPM as a complication, and in turn, SPM can cause diffuse subcutaneous emphysema and pneumothorax. This worsens the prognosis further. ${ }^{13,19}$ There is no special treatment for SPM, in addition to COVID-19 treatment, and conservative treatment is continued. Patients who develop SPM should be carefully monitored because it could potentially cause respiratory and circulatory problems. Because pneumothorax may develop, chest radiography should be performed every day. Tube thoracostomy treatment was performed when the ratio of pneumothorax was more than $10 \%$ and observation and oxygen treatment were performed when the ratio of pneumothorax was $10 \%$ or less. The two-bottle technique can be used to prevent viral spread in those undergoing tube thoracostomy. The main principle of the treatment of 
subcutaneous emphysema is repairing of lung parenchyma by leaking air and preventing the air to run under the skin and being taken out the present air under the skin. It can be resolved by soft tissues gradually with $100 \%$ treatment of oxygen in cases of mild-moderate subcutaneous emphysema. ${ }^{7,20,21}$ In this study, $70 \%$ of Group B patients had accompanying subcutaneous emphysema and $20 \%$ had accompanying pneumothorax. SPM developed $3.4 \pm 6.7$ days on average after the COVID-19 diagnosis was made. Radiological disappearance of SPM occurred in $4.6 \pm 1.8$ days on an average. While the rate of mechanical ventilation requirement was $60 \%$ in Group B patients, this rate was $0 \%$ in Group A patients. Furthermore, while the rate of exitus was $60 \%$ in Group B patients, it was $4 \%$ in Group A patients. The mean age of these patients with exitus was reported to be $60.3 \pm 10.3$. The length of hospital stay was 20.5 days in Group B and 9 days in Group A.

This study has several limitations. First, the study includes retrospective and single-centre results. Second, the sample size was relatively limited. However, it is the largest series that includes SPM in patients with COVID-19 pneumonia in the literature.

\section{CONCLUSION}

When SPM develops in a non-pandemic patient, it is usually a self-limiting condition. However, when it develops in a patient with COVID-19 pneumonia, it is a sign that the prognosis will not be good, and these patients need a more aggressive treatment. High serum ferritin and CRP level in consecutive measurements might signify an elevated risk of SPM in patients with COVID-19 pneumonia.

\section{ACKNOWLEDGMENT:}

The authors are grateful to Ertan Koc, Statistician, for statistical support.

\section{ETHICAL APPROVAL:}

The study was approved by local Ethics Commitee (Date: 01.10.2020/ No: 165).

\section{PATIENTS' CONSENT:}

Written informed consents were obtained from all participants.

\section{CONFLICT OF INTEREST:}

The authors declared no conflict of interest.

\section{AUTHORS' CONTRIBUTION:}

IEO: Conception of the work, analysis or interpretation of data for the work, discussion and literature review.

MAT: Data analysis, results, and discussion.

SG: Literature search, analysis and interpretation of data.

ATO: Conception and design, and acquisition of data.
1. Zhu N, Zhang D, Wang W, Li X, Yang B, Song J, et al. A novel coronavirus from patients with pneumonia in china, 2019. $N$ Engl J Med 2020; 382:727-33. doi: 10.1056/NEJMoa200 1017.

2. Wu C, Chen X, Cai Y, Xia J, Zhou X, Xu S, et al. Risk factors associated with acute respiratory distress syndrome and death in patients with coronavirus disease 2019 pneumonia in Wuhan, China. JAMA Intern Med 2020; 180(7):934-43. doi: 10.1001/jamainternmed.2020.0994

3. Huang $P$, Liu T, Huang L, Liu H, Lei M, Xu W, et al. Use of chest CT in combination with negative RT-PCR assay for the 2019 novel coronavirus but high clinical suspicion. Radiology 2020; 295(1):22-23. doi: 10.1148/radiol.2020200330.

4. Xie X, Zhong Z, Zhao W, Zheng C, Wang F, Liu J. Chest CT for typical 2019-nCoV pneumonia: Relationship to negative RT-PCR testing. Radiology 2020; 296(2):E41-E5. doi: 10.1148/ radiol.2020200343.

5. Tezcan MA, Özsoy IE. Hamman's Syndrome (Spontaneous Pneumomediastinum). Harran University Medical Faculty 2019; 16:443-47. doi: 10.35440/hutfd.631339.

6. Mohan V, Tauseen RA. Spontaneous pneumomediastinum in COVID-19. BMJ Case Rep 2020; 13(5):e236519. doi: 10.1136/bcr-2020-236519.

7. Zhou C, Gao C, Xie Y, Xu M. COVID-19 with spontaneous pneumomediastinum. Lancet Infect Dis 2020; 20(4):510. doi: 10.1016/S1473-3099(20)30156-0.

8. Azer SA. COVID-19: Pathophysiology, diagnosis, complications and investigational therapeutics. New Microbe and New Infect 2020; 37:100738. doi: 10.1016/j.nmni.2020. 100738.

9. Takada K, Matsumoto S, Hiramatsu T, Kojima E, Watanabe $\mathrm{H}$, Sizu $M$, et al. Management of spontaneous pneumomediastinum based on clinical experience of 25 cases. Respir Med 2008; 102(9):1329-34. doi: 10.1016/j.rmed.2008. 03.023.

10. Ralp-Edwards AC, Pearson FG. Atypical presentation of spontaneous pneumomediastinum. Ann Thorac Surg 1994; 58(6):1758-60. doi: 10.1016/0003-4975(94)91683-7.

11. Hamman L. Spontaneous mediastinal emphysema. Bull Johns Hopkins Hosp 1939; 64;1-21.

12. Koullias GJ, Korkolis DP, Wang XJ, Hammond GL. Current assessment and management of spontaneous pneumomediastinum: Experience in 24 adult patients. Eur J Cardiothorac Surg 2004; 25(5):852-5. doi: 10.1016/j.ejcts.2004.01.042.

13. Meireles J, Neves S, Castro A, Franca M. Spontaneous pneumomediastinum revisited. Respir Med CME 2011; 4(4):181-3. doi.org/10.1016/j.rmedc.2011.03.005.

14. World Health Organization. Coronavirus Disease (COVID-19) weekly epidemiological updates. 2020 (internet publication).

15. Figliozzi S, Masci PG, Ahmadi N, Tondi L, Koutli E, Aimo A, et al. Predictors of adverse prognosis in Covid-19: A systematic review and meta-analysis. Eur J Clin Invest 2020; 50(10):e13362. doi: 10.1111/eci.13362.

16. Arshad AR, Khan I, Shahzad K, Arshad M, Haider SJ, Aslam MJ. Association of Inflammatory Markers with Mortality in COVID-19 Infection. JCPSP 2020; 30(10):S158-S163. doi:

\section{REFERENCES}


10.29271/jcpsp.2020.supp2.S158.

17. Akçay Ş, Özlü T, Yılmaz A. Radiological approaches to COVID-19 pneumonia. Turk J Med Sci 2020; 50(SI-1): 604-10. doi: 10.3906/sag-2004-160.

18. Dong J, Peng H, Zhang D. Early clinical and CT manifestations of coronavirus disease 2019 (COVID-19) pneumonia. AJR Am J Roentgenol 2020; 215(2):338-43. doi: 10.2214/AJR.20.22961.

19. Chekkoth SM, Supreeth RN, Valsala N, Kumar P, Raja RS. Spontaneous pneumomediastinum in H1N1 infection: uncommon complication of a common infection. J $R$ Coll of
Physicians Edinb 2019; 49(4):298. doi: 10.4997/JRCPE.2019.409.

20. Ceylan KC, Batıhan G, Yazgan S, Gürsoy S, Kıraklı SC, Ataman S. Pleural complications in patients with coronavirus disease 2019 (COVID-19): How to safely apply and follow-up with a chest tube during the pandemic? Eur J Cardiothorac Surg 2020; 58(6):1216-21. doi: 10.1093/ejcts/ezaa356.

21. Volpi_S, Ali JM, Suleman A, Ahmed RN._Pneumomediastinum in COVID-19 patients: A case series of a rare complication. Eur J Cardiothorac Surg 2020; 58(3):646-47. doi: 10.1093/ejcts/ezaa222. 